\title{
PENGARUH KEDALAMAN DRAINASE VERTIKAL SATU ARAH MENGGUNAKAN KOLOM PASIR TERHADAP KECEPATAN PENURUNAN DAN PERUBAHAN KADAR AIR TANAH LUNAK
}

\author{
Baggus Prastyo 1), Bambang Setiawan 2), Raden Harya Dananjaya Hesti Indrabaskara ${ }^{3)}$ \\ 1) Mahasiswa Fakultas Teknik, Program Studi Teknik Sipil, Universitas Sebelas Maret Surakarta \\ 2) 3) Pengajar Fakultas Teknik, Program Studi Teknik Sipil, Universitas Sebelas Maret Surakarta \\ Jalan Ir.Sutami 36A Surakarta 57126. Telp.0271-647069. Email: baggusprastyo@gmail.com
}

\begin{abstract}
Soil properties should be considered before structure constructions, because not all of soil type is appropriate to be used. The problem of structure is occurred caused by its embankment of soft soil. The aim of this research is to find out the behaviour of soft soil which is applicated with sand column as vertical drain. It could be seen from the settlement which occurs after axial loads are applied on soft soil with and without vertical drain. Research done by giving $40 \mathrm{~kg}$ axial loads on soft soil. Results show that $C_{v}$ value of $5 / 6$ deep ratio sand column vertical drains is $0,14 \mathrm{~cm}^{2} /$ second and $1 / 2$ deep ratio sand column vertical drains is $0,16 \mathrm{~cm}^{2} /$ second, and $C_{c}$ value is 0,42 and 0,40. 5/6 deep ratio sand column vertical drain's settlement speed is 19,78\% faster.
\end{abstract}

Keywords: soft soil, settlement, vertical drain, sand column

\begin{abstract}
Abstrak
Pembangunan konstruksi suatu struktur harus mempertimbangkan sifat-sifat tanah sebelum mendirikan bangunan tersebut, dikarenakan tidak semua jenis tanah memiliki sifat yang baik. Permasalahan konstruksi suatu struktur akibat tanah lunak terjadi pada tanah timbunan. Penelitian ditujukan untuk melihat perilaku penambahan kolom pasir sebagai drainase vertikal pada tanah lunak yang dilihat dari besar penurunan secara akumulatif dalam durasi selama 21 hari dengan kolom kelompok dengan variasi rasio kedalaman. Pengujian dilakukan dengan pemberian beban sebesar $40 \mathrm{~kg}$ pada tanah. Hasil penelitian menunjukkan nilai $\mathrm{C}_{\mathrm{v}}$ pada drainase vertikal rasio kedalaman $5 / 6$ adalah $0,14 \mathrm{~cm}^{2} /$ detik dan untuk rasio kedalaman $1 / 2$ adalah $0,16 \mathrm{~cm}^{2} /$ detik, dan nilai $\mathrm{C}_{\mathrm{c}}$ untuk kedua pemodelan adalah 0,42 dan 0,40. Kecepatan penurunan drainase vertikal kedalaman rasio 5/6 19,78\% lebih cepat.
\end{abstract}

Kata kunci: tanah lunak, penurunan, drainase vertikal, kolom pasir.

\section{PENDAHULUAN}

Pekerjaan suatu kontruksi bangunan sering kali diawali dengan pekerjaan timbunan, seringkali tanah yang digunakan adalah tanah lunak yang banyak memiliki butiran halus dan salah satu permasalahan yang muncul pada pekerjaan timbunan tanah lunak adalah terjadinya penurunan tanah (settlement), salah satu cara untuk mengatasi permasalahan ini adalah dengan mempercepat proses penurunan tanah menggunakan metode pembebanan (loading) disertai pemasangan drainase vertikal (vertical drain). Drainase vertikal mempercepat aliran air pori pada timbunan tanah lunak dengan memperpendek aliran arah vertikal ke arah horisontal dan air pori akan mengalir lebih cepat melalui medium drainase vertikal yang memiliki permeabilitas yang lebih tinggi dibanding tanah lunak. Drainase vertikal saat ini dibuat menggunakan bahan fabrikasi yang lebih dikenal dengan Prefabricated Vertical Drain (PVD), namun pemasangan PVD memerlukan biaya yang tinggi dan alat berat yang memiliki keterbatasan mobilitas sehingga untuk daerah tertentu semisal perumahan dan perkampungan, pemakaian PVD ini akan mengalami banyak kendala. Pasir merupakan bahan yang relatif mudah didapatkan di Indonesia dan memiliki permeabilitas yang tinggi serta sebelum penggunaan PVD pasir terlebih dahulu menjadi bahan sebagai drainase vertikal. Penelitian terdahulu telah mengkaji drainase menggunakan kolom pasir baik pengaruh jarak maupun pengaruh diameter dan didapatkan hasil bahwa masih banyak variasi yang dilakukan terhadap drainase vertikal kolom pasir serta penggunaanya memungkinkan untuk solusi penurunan tanah terutama di proyek dengan dana minim maupun akses yang terbatas. 


\section{TINJAUAN PUSTAKA DAN LANDASAN TEORI}

Penelitian tentang penggunaan kolom pasir sebagai drainase vertikal telah dilakukan bahkan dengan skala besar seperti yang dilakukan oleh Sudarto, (2013) tentang perbaikan tanah lunak menggunakan metode drainase vertikal kolom pasir untuk badan jalan, dari penelitiannya didapatkan hasil bahwa penggunaan kolom pasir sebagai drainase vertikal dapat mereduksi waktu proses konsolidasi yang terjadi. Pola dan jarak pemasangan juga berpengaruh dalam besarnya reduksi.

Penelitian mengenai pengaruh kolom pasir terhadap konsolidasi tanah lunak dilakukan juga oleh Listyawan dkk, (2015) didalam penelelitian ini kolom pasir digunakan untuk mempercepat proses konsolidasi pada tanah lunak. Kolom pasir diletakan pada tepi timbunan tanah lunak kemudian diambil sampel dari jarak tertentu dari kolom pasir. Dari penelitian ini didapatkan hasil yang menunjukan semakin jauh sampel yang diambil dari kolom pasir kecepatan konsolidasi semakin menurun.

\section{Tanah Lunak}

Tanah lunak dalam Hardiyatmo (2002) adalah merupakan tanah lempung kohesif yang mempunyai daya dukung lebih kecil dari $0,5 \mathrm{~kg} / \mathrm{cm}^{2}$ dan nilai standard penetration test lebih kecil dari 4 (N-volume $<4$ ). Berdasarkan uji lapangan, tanah lunak secara fisik dapat diremas dengan mudah oleh jari-jari tangan. Sifat umum tanah lunak adalah memiliki kadar air $60-110 \%$, batas cair $60-100 \%$, batas plastis $30-50 \%$, saat dites sieve analysis, maka butiran yang lolos oleh saringan no 200 akan lebih besar dari 85\% serta memiliki kuat geser $20-40 \mathrm{kN} / \mathrm{m}^{2}$. Peck dkk (1953) menyatakan bahwa tanah lunak dapat diidentifikasi ketika dapat ditembus menggunakan ibu jari dengan kedalaman beberapa inchi dan memiliki kiuat geser tekan bebas $(\mathrm{Qu})$ sebesar $0,25 \mathrm{~kg} / \mathrm{cm}^{2}$ hingga $0,5 \mathrm{~kg} / \mathrm{cm}^{2}$.

\section{Drainase Vertikal (Vertical Drain)}

Metoda drainase vertikal ini sering diterapkan bersama-sama dengan metoda pemberian beban awal (preloading). Pada perencanaan perbaikan tanah ini, untuk drainase vertikal menggunakan kolom pasir atau sand column. Drainase vertikal memperpendek aliran air pori akibat pembebebanan yang semula secara vertikal melalui pori - pori tanah lunak dengan permeabilitas yang rendah dapat mengalir secara horizontal menuju media dengan permeabilitas yang lebih tinggi dan meresap secara vertikal ke permukaan.

\section{Desain Drainase Vertikal}

Diameter drainase pasir vertikal bervariasi kira-kira $45 \mathrm{~cm}$ sampai $60 \mathrm{~cm}$. Diameter yang terlalu kecil dihindarkan, karena kesulitan pengisian pasir pada pipa mandrel. Drainase vertikal dengan tipe drainase pasir dan cara pemasangan menggunakan batang berlubang flight auger sebagaimana yang dinyatakan Hardiyatmo (2015) memiliki spesifikasi diameter 0,3 hingga 0,5 m dengan jarak tipikal antar drainase vertikal 2 hingga 5 meter dan kedalaman maksimal $35 \mathrm{~m}$.

\section{METODE PENELITIAN}

Hasil penelitian didapatkan menggunakan berbagai macam pemeriksaan untuk mendapatkan data-data yang diperlukan. Pemeriksaan yang akan dilakukan pada penelitian ini meliputi, pemeriksaan tanah yang tidak diberi kolom pasir dan yang diberi kolom pasir kedalaman $15 \mathrm{~cm}$ dan $25 \mathrm{~cm}$ dengan pengujian penurunan permukaan, perubahan kadar air, nilai koefisien konsolidasi tanah $\left(\mathrm{C}_{\mathrm{v}}\right)$, dan indeks pemampatan $\left(\mathrm{C}_{\mathrm{c}}\right)$. Sampel tanah diambil di Desa Bulakmanyar Kecamatan Sumberlawang Kabupaten Sragen, berdasarkan pengujian diketahui bahwa tanah di daerah ini merupakan tanah lunak. Peralatan yang digunakan pada penelitian ini berupa drum besi sebagai media utama pemodelan menggunakan bantuan jangka sorong untuk mengukur penurunan tanah dan alat bantu lainya untuk menguji kadar air dan pengujian konsolidasi.

\section{Tahapan Pengujian}

Tahap pengujian dilakukan percobaan konsolidasi tanah lunak tanpa kolom pasir sebagai pemodelan A dan dengan kolom pasir. Pada pengujian konsolidasi tanah lunak tanpa kolom pasir, pada tahap pertama menyiapkan drum pengujian lalu memasukkan sampel tanah hingga ketinggian tanah mencapai $30 \mathrm{~cm}$ padat secara bertahap 3 lapis dengan tebal lapisan $10 \mathrm{~cm}$ per lapis, kemudian ambil sampel tanah untuk dilakukan pengujian konsolidasi sebelum pembebanan. Pada pengujian dengan kolom pasir tanah dilubangi dengan pipa stainless dengan diameter $2,5 \mathrm{~cm}$ dengan kedalaman $15 \mathrm{~cm}$ pada drum pertama sebagai pemodelan B yaitu rasio kedalaman drainase vertikal $1 / 2$ dan $25 \mathrm{~cm}$ pada drum kedua sebagai pemodelan $C$ yaitu rasio kedalamn drainase vertikal 5/6. Lubang di masukkan pasir kedalamnya sampai kepermukaan, kemudian pada permukaan di beri lapisan pasir setebal $3 \mathrm{~cm}$, dan diatas lapisan pasir diletakkan plat baja setebal $4 \mathrm{~mm}$ dengan diameter $40 \mathrm{~cm}$. 


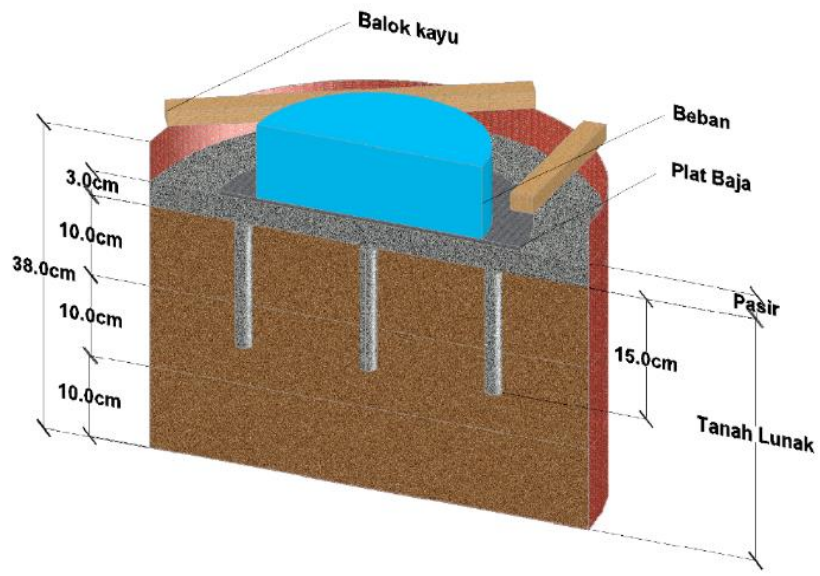

(a)

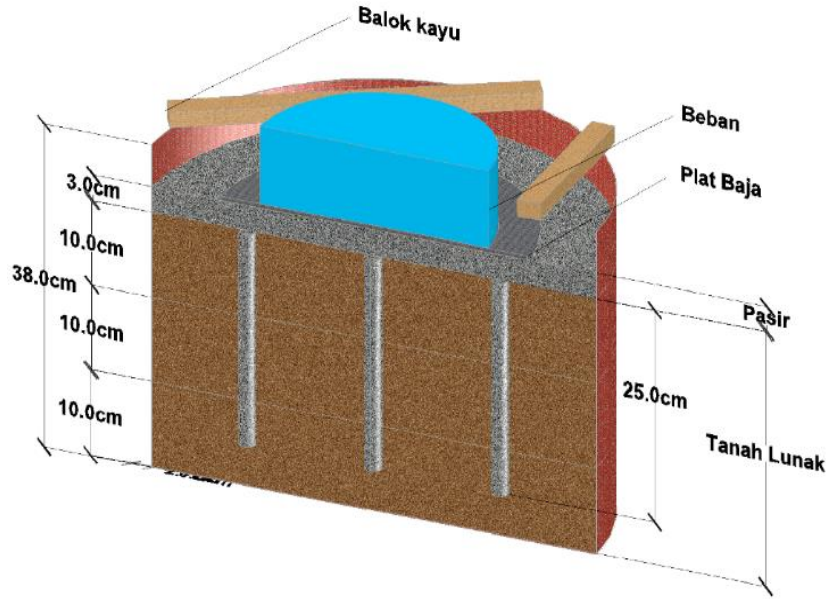

(b)

Gambar 1. Variasi model pengujian (a) drainase vertikal kolom kelompok satu arah rasio kedalaman $1 / 2$ (b) drainase vertikal kolom kelompok satu arah rasio kedalaman 5/6

Pengujian dimulai dengan diletakkanya beban seberat $40 \mathrm{~kg}$ pada plat baja, kemudian dilakukan pengukuran jarak balok kayu referensi terhadap plat baja. Pengukuran dilakukan setiap harinya pada waktu yang sama untuk mengetahui besar penurunan setiap harinya. Selain melakukan pengukuran penurunan dilakukan pula pengukuran hambatan listrik lapisan pasir permukaan, kadar air pasir lapisan permukaan, dan kadar air dalam tanah. Pengujian dilakukan selama 21 hari agar dapat dilihat penurunan yang terjadi secara lebih mendetail serta data yang didapatkan lebih teliti, selain itu pengujian pendahuluan dengan skala yang lebih kecil menujukkan penurunan mendekati kondisi asimtut pada hari ke 7, sehingga untuk skala penelitian digunakan durasi selama 21 hari. Beban dengan berat $40 \mathrm{~kg}$ diangkat setelah masa pembebanan kemudian diambil sampel pada masing - masing drum untuk dilakukan pengujian konsolidasi setelah pembebanan.

\section{ANALISIS DATA DAN PEMBAHASAN}

\section{Uji Sifat Fisik Tanah}

Pengujian sifat fisik tanah yang dilakukan memberikan hasil bahwa tanah memiliki nilai batas cair (liquid limit) sebesar $79,76 \%$ dan batas plastis (plastic limit) sebesar 34,93\%, memiliki persentase lolos saringan 200 sebesar 86,72\% dan kadar air saat pengujian adalah $60 \%$, dari data tersebut maka tanah memenuhi syarat sebagai tanah lunak.

\section{Pengujian Penurunan Tanah}

Pengamatan penurunan dilakukan untuk mengetahui pengaruh dari penambahan variabel maupun pengubahan variabel yang dilakukan dalam pemodelan. Penurunan dari ketiga pemodelan dapat dilihat pada Gambar 2.

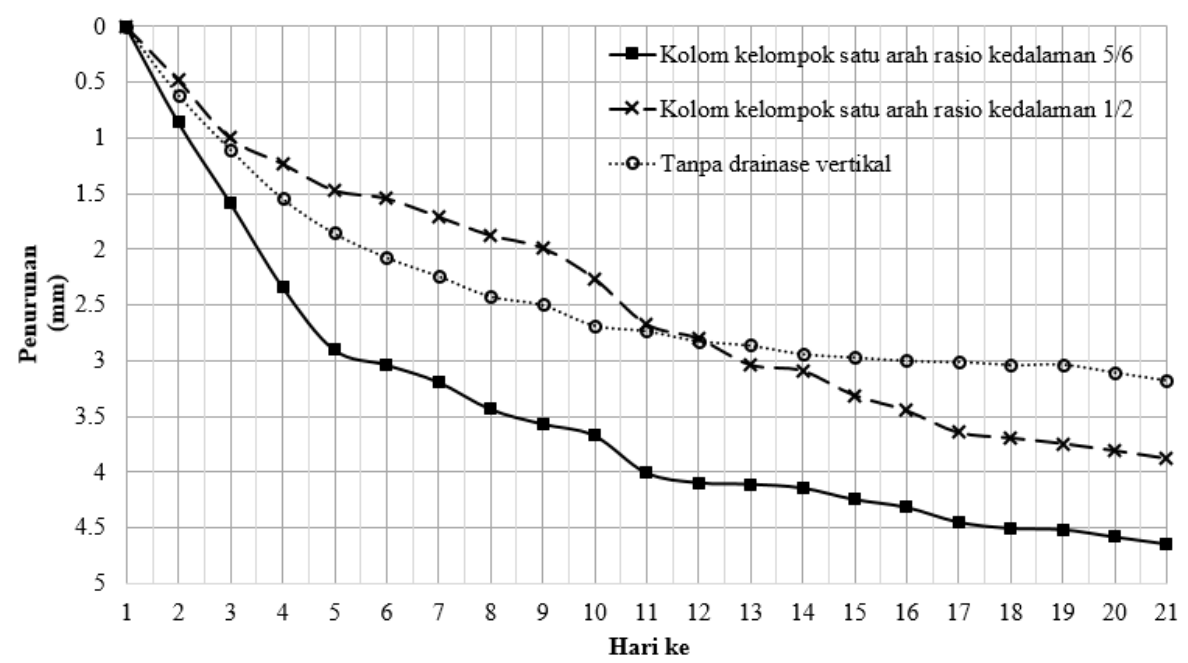

Gambar 2. Perbandingan penurunan tanah ketiga pemodelan 
Penurunan yang terjadi pada pemodelan B selama 21 hari adalah sebesar 3,88 mm, penurunan ini memiliki selisih $0,71 \mathrm{~mm}$ lebih besar dibanding dengan penurunan pada pemodelan A yang berarti $22,22 \%$ lebih besar, ini menunjukkan dengan menambahakan drainase vertikal pada tanah lunak akan meningkatkan kecepatan penurunanya. Penurunan pada pemodelan $C$ selama 21 hari adalah sebesar 4,64 mm, penurunan ini memiliki selisih 1,47 mm lebih besar dibanding penurunan pada pemodelan A yang berarti 46,39\% lebih besar, dan memiliki selisih $0,77 \mathrm{~mm}$ lebih besar dibading penurunan pada pemodelan B yang berarti 19,78\% lebih besar pula, ini menunjukkan dengan menambah kedalaman drainase vertikal mampu meningkatkan kecepatan penurunan pada tanah lunak

\section{Perubahan Kadar Air}

Kadar Air Pasir Permukaan

Pengujian kadar air yang dilakukan mendapatkan data yang fluktuatif sehingga untuk mempermudah pembacaan dibuat kurva regresi dari data yang ada. Kurva log kemudian dibandingkan antara satu sama lain menjadi satu. Gambar 3 menunjukkan perubahan kadar air yang terjadi pada setiap model.

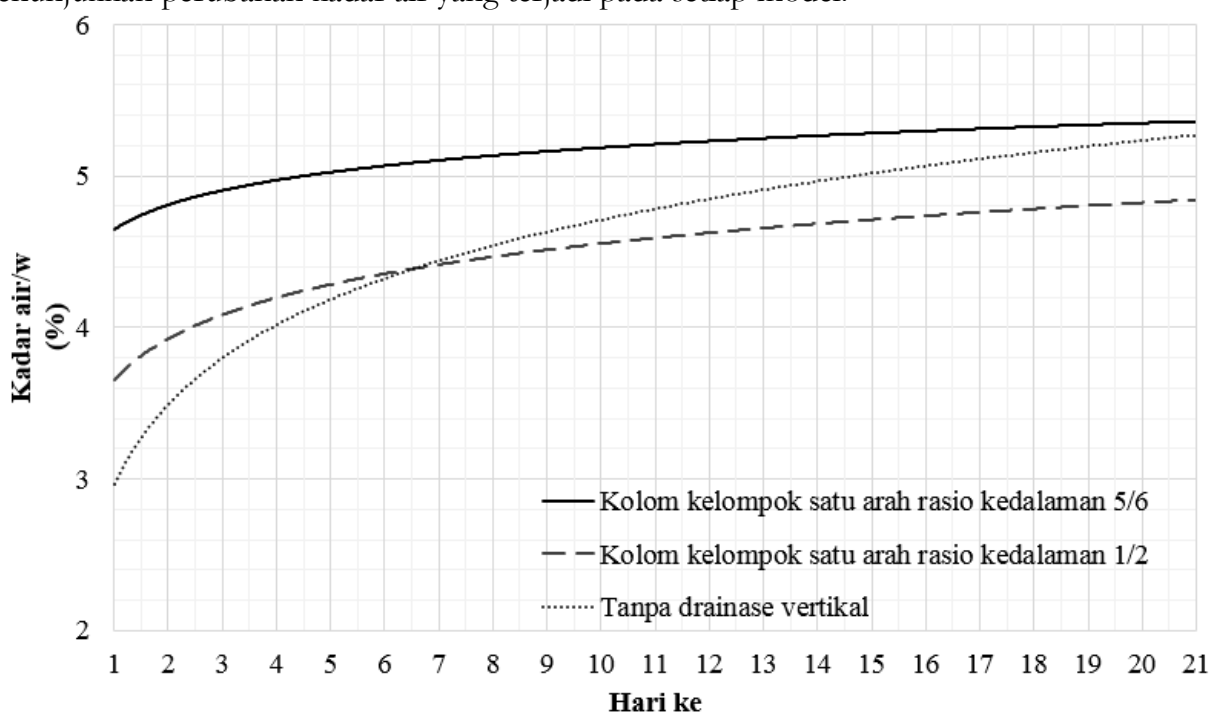

Gambar 3. Perubahan kadar air lapisan pasir permukaan pada ketiga pemodelan

Gambar 3 menunjukkan bahwa rata - rata paling besar dimiliki oleh pemodelan C, kemudian disusul oleh pemodelan A setelah itu pemodelan B. Kadar air rata - rata dari pemodelan C adalah sebesar 5,15\%, sedangkan pada pemodelan A dan B tidak jauh berbeda yaitu 4,60\% dan 4,50\%, namun dari semua pemodelan memiliki pencapaian kadar air stabil yang berbeda. Pemodelan A mencapai kesetabilan kadar air pada hari ke 15, pemodelan B pada hari ke 11, dan pemodelan $\mathrm{C}$ pada hari ke 5.

Kadar Air Tanah

Pengujian kadar air yang dilakukan mendapatkan data yang fluktuatif sehingga untuk mempermudah pembacaan dibuat kurva regresi dari data yang ada. Gambar 4 menunjukkan perubahan kadar air tanah yang terjadi pada setiap model.

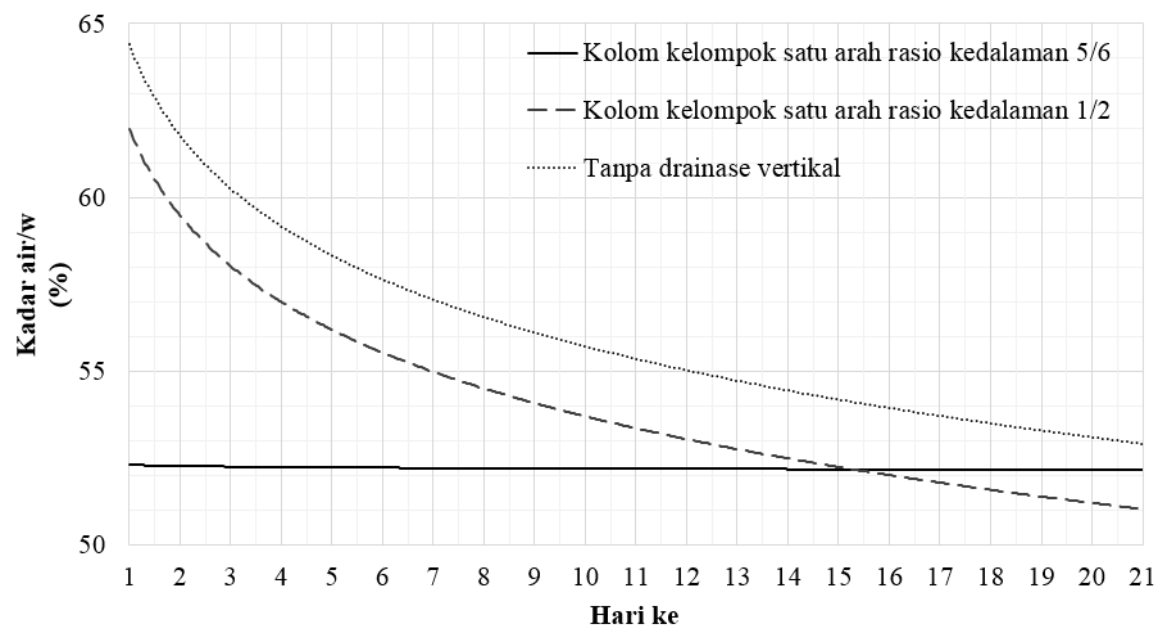

Gambar 4. Perubahan kadar air tanah pada ketiga pemodelan 
Gambar 4 menunjukkan bahwa rata - rata kadar air tanah paling rendah dimiliki oleh pemodelan $\mathrm{C}$ yaitu sebesar 52,21\% kemudian kadar air terendah kedua dimiliki pemodelan B yaitu sebesar 54,83\%, kemudian kadar air pemodelan A memiliki kadar air tanah paling besar yaitu 56,90\%. Penurunan pada pemodelan A mencapai kondisi kadar air stabil pada hari ke 10 pada pemodelan B pada hari ke 7 dan pada pemodelan $C$ sebelum hari ke 4, ini menunjukkan bahwa dengan menambahkan drainase vertikal kolom pasir akan mempercepat proses perembesan air tanah keluar, dan dengan memperdalam drainase vertikal maka jalur horizontal air dalam tanah juga lebih besar sehingga kecepatan resapan air makin meningkat.

\section{Pengujian Konsolidasi}

Pengujian konsolidasi dilakukan pada sampel tanah sebelum pembebanan dan juga setelah pembebanan baik dari sampel tiap pemodelan didapat kan nilai $C_{v}$ dan $C_{c}$ dari setiap model pengujian ditunjukkan pada Tabel 1.

Tabel 1. Nilai $C_{v}$ dan $C_{c}$ tiap pemodelan

\begin{tabular}{cccc}
\hline No & Sampel & $\mathbf{C}_{\mathbf{v}}$ & $\mathbf{C}_{\mathbf{c}}$ \\
\hline 1 & Sebelum sebelum terdrainase & 0,79 & 0,38 \\
2 & Tanpa drainase vertical setelah terdrainase & 0,33 & 0,39 \\
3 & Kolom kelompok satu arah rasio kedalaman 1/2 setelah terdrainase & 0,16 & 0,40 \\
4 & Kolom kelompok satu arah rasio kedalaman 5/6 setelah terdrainase & 0,14 & 0,42 \\
\hline
\end{tabular}

Tabel 1 menunjukkan bahwa nilai $C_{v}$ pada sebelum terdrainase akibat pembebanan adalah sebesar $0,79 \mathrm{~cm}^{2} / \mathrm{detik}_{\text {, }}$ dan setelah pembebanan pada model A adalah sebesar $0,33 \mathrm{~cm}^{2} /$ detik, pada model B adalah sebesar $0,16 \mathrm{~cm}^{2} / \mathrm{detik}_{\text {, }}$ dan pada model $\mathrm{C}$ adalah sebesar $0,14 \mathrm{~cm}^{2} /$ detik. Ini menunjukkan bahwa pada model $\mathrm{C}$ mengalami pemampatan yang terbesar sehingga ketika dilakukan uji konsolidasi hanya mengalami sedikit penurunan. Nilai $\mathrm{C}_{\mathrm{c}}$ pada sebelum pengujian adalah sebesar 0,38 , dan setelah pembebanan pada model $\mathrm{A}$ adalah sebesar 0,39 , pada model $\mathrm{B}$ adalah sebesar 0,40 , dan pada model $\mathrm{C}$ adalah sebesar 0,42 . Ini menunjukkan bahwa pada model $\mathrm{C}$ telah mengalami pemampatan yang terbesar sehingga memiliki nilai $\mathrm{C}_{\mathrm{c}}$ tertinggi.

\section{Pembandingan hasil pengamatan dengan analisa teori Terzaghi}

Analisa teori dengan teori Terzaghi dilakukan untuk membandingkan antara hasil eksperimental dengan analisa. Hasil perhitungan penurunan dengan analisis teori untuk setiap pemodelan ditujukan pada Gambar 6.

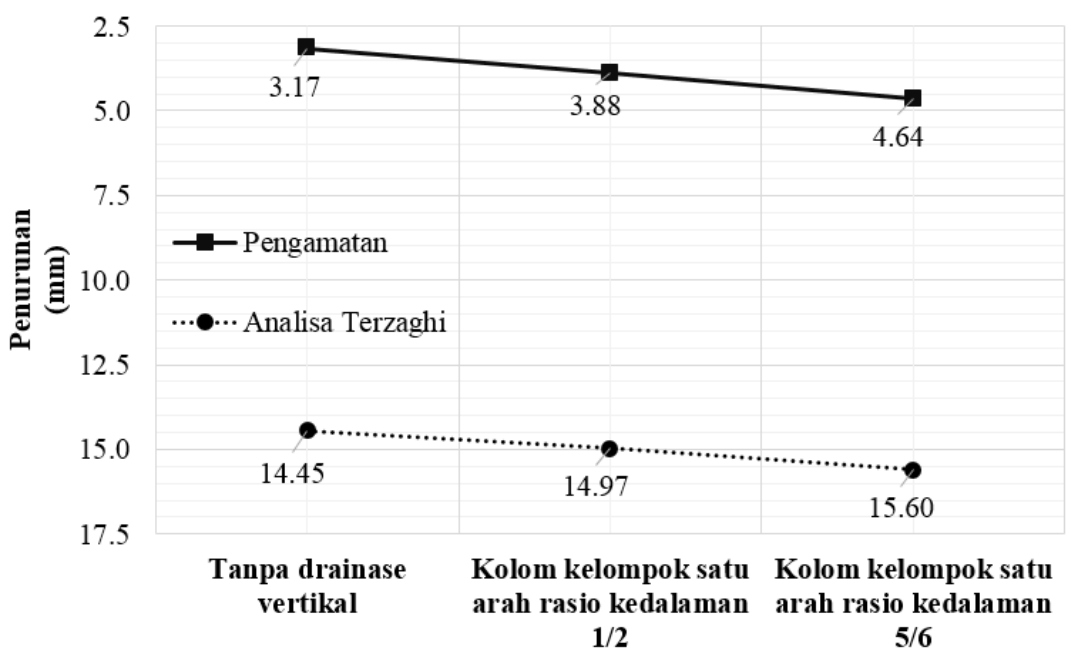

Gambar 6. Perbandingan penurunan hasil pengamatan dengan analisa Terzaghi (1967)

Gambar 6 menunjukkan adanya selisih yang cukup besar antara hasil pengamatan dengan analisa perhitungan Terzaghi, namun korelasi antara keduanya sama dimana semakin dalam drainase vertikal maka penurunan semakin besar. Penurunan terbesar terjadi pada model drainase vertikal kolom kelompok satu arah rasio kedalaman 5/6 yakni sebesar 4,64 mm secara pengamatan dan 15,60 mm dengan metode analisis. Penurunan yang dialami model drainase vertikal kolom kelompok satu arah rasio kedalaman $1 / 2$ adalah sebesar 3,88 mm secara pengamatan dan 14,97 mm dengan metode analisis. Penurunan terkecil terjadi pada model tanpa drainase vertikal yaitu sebesar 3,17 mm secara pengamatan dan 14,45 mm dengan metode analisis hitungan. 


\section{KESIMPULAN}

Berdasarkan analisa data dan pembahasan dari hasil pengujian beton mutu tinggi memadat mandiri dengan variasi komposisi abu sekam padi, maka dapat ditarik kesimpulan sebagai berikut:

1. Penambahan drainase vertikal dengan rasio kedalaman 5/6 terhadap ketebalan lapisan tanah lunak meningkatkan kecepatan penurunan sebesar 46,39 \%, sedangkan drainase vertikal dengan rasio kedalaman $1 / 2$ terhadap ketebalan lapisan tanah lunak meningkatkan penurunan sebesar 22,22 \%, penambahan drainase vertikal mempercepat penurunan tanah.

2. Drainase vertikal dengan rasio kedalaman 5/6 terhadap ketebalan lapisan tanah lunak memiliki kecepatan 19,78 $\%$ lebih cepat dibanding drainase vertikal dengan rasio kedalama 1/2 terhadap ketebalan lapisan tanah lunak, semakin dalam drainase vertikal maka penurunan semakin cepat.

3. Penurunan tanah diiringi dengan meningkatnya kadar air lapisan pasir dan penurunan kadar air tanah yang sebanding dengan kedalaman drainase vertikal.

\section{DAFTAR PUSTAKA}

Hardiyatmo, H. C., 2002. Teknik Fondasi 1. Yogyakarta: Gadjah Mada University Press.

Hardiyatmo, H. C., 2015. Geosintetik Untuk Rekayasa Jalan Raya: Perancangan Dan Aplikasi. Yogyakarta: Gadjah Mada University Press.

Listyawan, A. B., Wiqoyah Q., Renaningsih, dan Satriyana, M. R. W., 2015, Pengaruh Kolom Pasir Terhadap Konsolidasi Tanah Lempung Lunak, Program Studi Teknik Sipil, Universitas Muhammadiyah Surakarta.

Peck, R. B., dan Terzaghi, K., 1967, Soil Mechanics in Engineering Practice, Wiley, New York

Sudarto, 2013, Perbaikan Tanah Lunak Dengan Vertical Sand Drain Method Untuk Badan Jalan, Program Studi Teknik Sipil, Universitas Soerjo Ngawi . 